\title{
Influence of Natural Gas Production Chemicals on Scale Production in MEG Regeneration Systems
}

\author{
A.Yong and E.O. Obanijesu* \\ Department of Chemical Engineering, Curtin University, Bentley Campus, Perth, W.A. 6102, Australia.
}

\begin{abstract}
Monoethylene glycol (MEG), a common hydrate inhibitor in natural gas transportation pipelines is usually regenerated and reused to minimize operating costs. In this study, three corrosion inhibitors and a scale inhibitor were investigated to understand how production chemicals contribute to scaling (salt loading) at pretreatment and reclamation sections of the regeneration process. The first set of study involved the use of ScaleSoftPitzer software to investigate the possibility of salt deposition at the pretreatment stage. Experiments were then conducted at pretreatment stage for inhibitor doses of $250 \mathrm{ppm}$ and $1000 \mathrm{ppm}$. The same sets of experiments were repeated by adding equal concentration of scale inhibitor with each corrosion inhibitor. In the second part of the study, rich MEG recovered from the pretreatment stage was regenerated by reconcentration and vacuum distillation techniques. The solids formed in the liquor were filtered, dried and weighed and the experiments performed at the pretreatment stage repeated. The results showed that level of scaling in the pretreatment stage was well predicted by the software. The experimental results were also consistent with the software predictions. Corrosion inhibitors produced salts that add up to the scaling problems while the scale inhibitor showed more adverse scaling effects comparatively. This is attributed to reduced hydration ability of scale inhibitors compared to corrosion inhibitors that contained smaller functional groups and large alkyl groups. Benzyl dimethyl hexadecylammonium chloride (B.D.H.C) showed higher scale formation ability compared to the other two corrosion inhibitors due to its polarity that influences its affinity for water. Alkalinity was another factor affecting scale formation; the higher the alkalinity, the higher the scale formation. Furthermore, the reclamation stage was found to be highly prone to corrosion and other impacts due to high total dissolved solids (TDS). Besides, a combination of corrosion and scale inhibitors in MEG regeneration system resulted in higher scaling effects compared to the effect of individual inhibitor due to the synergistic interaction between the two inhibitors. The findings of this study show significant implications in large scale continuous operation where salts dissolved in MEG could precipitate to cause scaling, corrosion and gunking amongst others. Escaping less soluble divalent ions are also capable of salting out downstream to cause the same problems within the pipeline and refinery. All these will adversely influence the process safety and the environment.
\end{abstract}

Keywords: MEG regeneration system; Subsea gas pipelines; Gas hydrates; Production chemicals; Flow assurance.

\section{* Correspondence Author}

E-mail address: e.obanijesu@curtin.edu.au; emmanuel257@yahoo.com

Tel: $\quad+61414512670$ 


\section{INTRODUCTION}

Formation of hydrates usually exposes subsea gas pipelines to disruption (Sandengen, 2006; Sharifi et al, 2014). This problem is responsible for an annual loss of hundreds of billions of dollars to gas industry with annual expenditure of over \$500,000,000 on methanol for inhibition (Daraboina et al, 2013). The industry has however replaced methanol with monoethylene glycol (MEG) because methanol is non recoverable and toxic (Obanijesu et al, 2014a). Though, both methanol and MEG are thermodynamic inhibitors which function by lowering the hydrate's freezing point; methanol's extreme solubility in water and hydrocarbons makes it poisonous to water habitat as well as enables it to contaminate the transported oil/gas (Van Son and Wallace, 2000). MEG however is recoverable, not as reactive as methanol and partially insoluble in hydrocarbon gas phase to eliminate the contamination problems (Brustad et al. 2005). Despite these qualities, a higher quantity of MEG is required per degree of hydrate suppression compared to that of methanol (Brustad et al. 2005). This necessitates the recovery of original MEG through regeneration process where a rich MEG (spent MEG's mixture with water or brine content greater than 25\%) is purified into lean MEG (Bikkina et al. 2012). The recovered MEG is recycled to minimise production cost.

MEG regeneration process is divided into pretreatment, reconcentration and reclamation sections (Sørli, 2010; Jonassen, 2013). The pretreatment section precipitates all divalent salts from the rich MEG. Here, hydrocarbons are firstly removed from the rich MEG stream in a flash drum, followed by raising the $\mathrm{pH}$ to 9.6 at temperature of $80{ }^{\circ} \mathrm{C}$ to precipitate the divalent salts. At the reconcentration section, the available water is boiled off at ambient pressure to generate lean MEG stream which is further purified in the reclamation section with a vacuum distillation. The salts formed in pretreatment and reclamation sections are usually separated using centrifuges. However, care must be taken while operating the regeneration process, as the use of high lean MEG weight percent (wt \%) could result in inadvertent increase of the rich MEG's boiling point and that of degradation of by-products in the reclamation section due to temperature surge (Psarrou et al., 2011).

On the other hand, various production chemicals are dosed into pipelines system during normal oil and gas production to inhibit flow assurance problems such as corrosion, scaling and wax deposition amongst others. However, investigations have confirmed that all 
production chemicals contain salt components (Latta et al., 2013). Corrosions, with an annual global economic loss of over $\$ 2.2$ trillion are minimized with anodic, cathodic, mixed and volatile corrosion inhibitors (Ajayi and Lyon, 2014; Nam et al, 2014). Chromates and nitrates salts are among the anodic inhibitors while silicates and phosphates salts are used as mixed corrosion inhibitors (Metrohm, 2011). Scales are generally formed as a result of the minerals in produced water exceeding their saturation limit due to fluctuations in operating temperature and pressure. Active sodium salt of a modified diamine phosphonate concentrate and active sodium salt of complex polyacrylate are used in preparation of organic scale inhibitors (Amjad et al, 2014; Kakadjian and Thompson, 2014). This study investigates the influence that these other production chemicals could have on salt production during the MEG regeneration process. This investigation is justified considering that these salts might dissolve in the MEG solution during the normal pipeline operations and precipitate during the regeneration process, contributing to its salt loading and generate scale production that will adversely affect the pretreatment and reclamation sections of the system. This work provides insights to pipeline industry on how the relative proportions of formation water to condensed water could affect precipitation at the pretreatment step as well as the impact of production chemicals on the scaling tendency of the remaining liquor during MEG flashing process.

\section{Methodology}

ScaleSoftPitzer software was firstly used to predict the trend of scale deposition in the pretreatment section of a MEG regeneration plant. Three corrosion inhibitors and one scale inhibitor were then experimentally investigated for their salt loading impacts on both the pretreatment and reclamation sections.

\subsection{Computational Scale Prediction - Theory and Software Application}

Many scientific attempts have been made to establish scale prediction models. Most of the models could only predict in part due to several complexities involved. Every active model considers the nature of the fluid such as phase (gaseous, liquid or aqueous) as well as if the fluid is hydrocarbon or not. It also establishes necessary thermodynamic relationship(s) between the phases by accounting for the fluid's pressure, temperature and composition. Smith et al (2004) used equation of state (EOS) to describe this thermodynamic relationship for the gas and liquid hydrocarbon phases in the form of the Soave Redlich Kwong (SRK) relation as 
$P=\frac{R T}{V-b}-\frac{a}{V(V+b)}$

Where $P, T$ and $V$ are the system's operating pressure, temperature and volume respectively; $R$ is the gas constant while $a$ and $b$ are pressure, temperature and composition dependants.

Smith et al (2004) further used the general Gibbs-Duhem Equations to present the thermodynamic relationship for the aqueous phase (Equation 2) which was modified by Radke (2014) as presented in Equation 3.

$S d T-V d P+\sum_{i=1}^{c} n_{i} d \mu_{i}=0$

$d U=T d S-P d V+\gamma d A+\sum_{i=1}^{c} \mu_{i} d n_{i}$

Where $S$ is the total system entropy, $U$ is the internal energy, $A$ is the differential interface area, $n_{i}$ is the total system moles of component $i, \mu_{i}$ is the chemical potential of component $i$ and $\gamma$ is the interfacial phase property.

Sandengen (2006) as presented in Equation (4) also relates EOS to fugacity in the hydrocarbon phase and Gibbs excess energy in the water.

$\mu_{i}=\mu_{i}^{o}+R T \ln \frac{f_{i}}{f_{i}^{o}}=\mu_{i}^{o}+R T \ln a_{i}$

Where $\mu^{o}$ and $f^{o}$ are respectively the chemical potential and fugacity in the standard state, $a_{i}$ is the activity of species $i$.

This study used the Scalesoftpitzer Software application to predict scaling in the pretreatment unit of the regeneration plant. Scalesoftpitzer is a program developed by the Brine Chemistry Consortium in Rice University to fully predict scaling in oilfield formation waters. The software is capable of predicting eleven scale types which are calcite $\left(\mathrm{CaCO}_{3}\right)$, barite $\left(\mathrm{BaSO}_{4}\right)$, gypsum $\left(\mathrm{CaSO}_{4} \cdot 2 \mathrm{H}_{2} \mathrm{O}\right)$, hemihydrate $\left(\mathrm{CaSO}_{4} \cdot 1 / 2 \mathrm{H}_{2} \mathrm{O}\right)$, anhydrate $\left(\mathrm{CaSO}_{4}\right)$, celestite $\left(\mathrm{SrSO}_{4}\right)$, fluorite $\left(\mathrm{CaF}_{2}\right)$, sphalerite $(\mathrm{ZnS})$, iron sulfide $(\mathrm{FeS})$, siderite $\left(\mathrm{FeCO}_{3}\right)$ and halite $(\mathrm{NaCl})$. The calculations involved in the program were based on Pitzer theory of electrolytes (Pitzer et al, 1961) and scaling tendency that is represented by the saturation index (S.I.) generated by the program. According to Kan et al (2001), the Pitzer model is the most widely accepted model to predict ion interactions in and it expresses the Gibbs excess energy as 
$\ln \left(Y_{M}\right)=\left(\frac{\frac{\delta G_{\text {Pitzer }}^{\text {express }}}{R T}}{\delta n_{i}}\right) T, P, n_{j}$

Where $Y_{M}$ is the Pitzer activity coefficient and $G_{\text {Pitzer }}^{\text {Excess }}$ is the excess free energy

Sandengen (2006) also considered the Pitzer coefficients but as functions of temperature, pressure, ionic strength and composition as presented in Equation 6

$\frac{G^{E}}{R T}=W_{w} f(I)+\frac{1}{W_{w}} \sum_{i j} \alpha_{i j}(I) n_{i} n_{j}+\frac{1}{W_{w}^{2}} \sum_{i j k} \mu_{i j k} n_{i} n_{j} n_{k}$

Where $G^{E}, W_{w}$ and n are the Gibb excess, weight of water and number of moles respectively, $\alpha_{i j}$ and $\mu_{i j k}$ are respectively the second and third virial coefficients in the Ptizer model and $f(I)$ that contains the Debye-Huckel limiting law is a function of ionic strength, temperature and solvent properties such as the dielectric constant.

Since MEG is the primary solvent for this study, the Pitzer equation as modified by Kan and Tomson (2012) was used. Equation 7 was then used to calculate the scaling tendency for calcite and other scaling types.

S.I. $($ calcite $)=\log _{10}\left(\frac{\text { ion activity product }}{K_{S p}(T, P)}\right)=\log _{10}\left(\frac{a_{c a 2+a} 0_{3}^{2-}}{K_{S p}^{c a l c i t e}(T, P)}\right)$

This index is not quantitative; it is just a prediction of tendency of the formation water or brine to precipitate. A negative S.I. (scaling index) value indicates that scaling will not form while a large positive value indicates the likelihood for scale to form. For each prediction, ion concentrations for each of the three brines synthesized for this study with its corresponding rich MEG content were inputted into the ScaleSoftPitzer software program. Table 1 was then used to determine the scaling risks based on the generated S.I. value.

Table 1: Indicating S.I. ranges on the level of scaling severity (Kan and Tomson, 2012)

\begin{tabular}{|l|l|}
\hline SI range & Severity \\
\hline S.I $<0$ & No scaling \\
\hline $0 \leq$ S.I $\leq 0.5$ & Low scaling risk \\
\hline $0.5 \leq$ S.I $\leq 1.0$ & Medium scaling risk \\
\hline $1.0 \leq$ S.I $\leq 2.5$ & High scaling risk \\
\hline
\end{tabular}




\subsection{Chemical Preparations}

\subsubsection{Chemicals}

The four investigated production chemicals are presented in Table 2. The three corrosion inhibitors were cetylpyridiniumchloride (C.P.C), docetylpyridiniumchloride (D.P.C) and Benzyl dimethyl hexadecylammonium chloride (B.D.H.C) while the scale inhibitor was phosphonnates aminotris (methylphosphonic acid) (A.T.M.P). The corrosion inhibitors, classified as film forming type are surfactants in nature with their molecules having hydrophilic and hydrophobic ends (Obanijesu et al, 2014b). C.P.C and D.P.C are in the family of pyridine compounds while B.D.H.C belongs to heterocyclic ammonium compound. A.T.M.P is a phosphonate based scale inhibitor (Kelland 2009).

Table 2: The investigated production chemicals

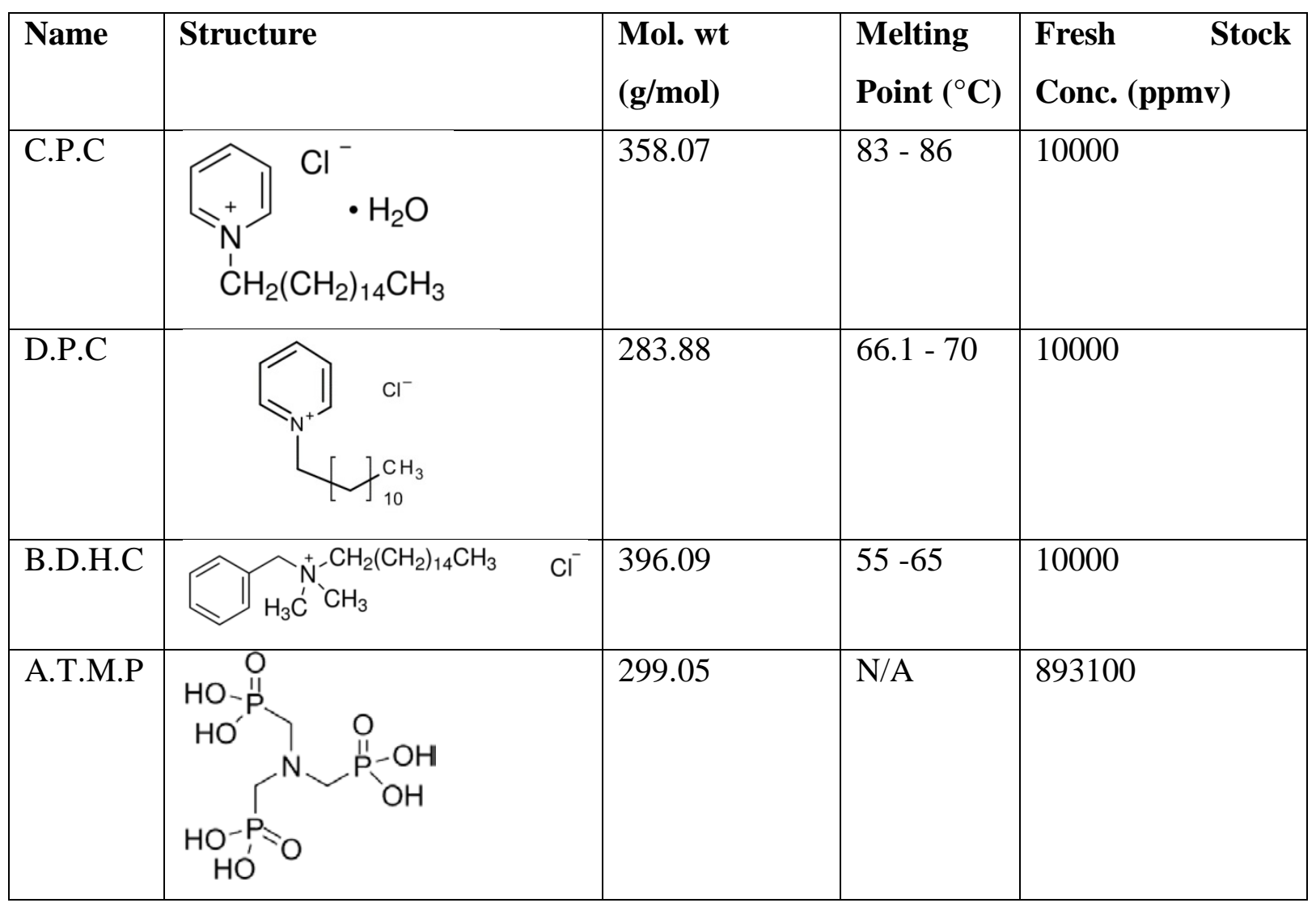




\subsubsection{Preparation of the Synthetic Brines}

The chemicals used to prepare the three brine solutions are listed in Table 3. Each salt was weighed on a Mettler Toledo scientific weighing balance with certainty of measurement of \pm $0.2 \mathrm{mg}$. Brine A is the composition of the condense water solution in the real-life MEG regeneration system while brine $B$ is that of the formation water (Table 4). They were individually prepared by dissolving the salts of quantities given in Table 5 into a 1 litre volumetric flask. The flask was then filled to mark with deionised water and stirred for 3 minutes to allow proper dissolution of the salt content. The brine solution was then passed through a fluted Whatman $185 \mathrm{~mm}$ filter paper to remove undissolved solids and the collected filtrate was labelled and stored. Brine C was prepared by mixing $50 \% \mathrm{v} / \mathrm{v}$ of brine $\mathrm{A}$ and brine $\mathrm{B}$.

Table 3: The list of chemical used for the study and their sources

\begin{tabular}{|l|l|l|l|}
\hline Chemical & Quality & Mole fraction & Source \\
\hline Sodium chloride & AR & 0.99 & Rowe Scientific Pty Ltd, Australia \\
\hline Potassium chloride & AR & 1.00 & Ajax Fine Chemicals Pty Ltd, Australia \\
\hline Calcium chloride & AR & 1.00 & Ajax Fine Chemicals Pty Ltd, Australia \\
\hline Sodium carbonate & AR & 0.99 & Ajax Fine Chemicals Pty Ltd, Australia \\
\hline Potassium chloride & AR & 1.00 & Ajax Fine Chemicals Pty Ltd, Australia \\
\hline Barium chloride & AR & 1.00 & Ajax Fine Chemicals Pty Ltd, Australia \\
\hline Sodium carbonate & AR & 0.99 & Sigma Chemicals Pty Ltd, Australia \\
\hline Ferric chloride & AR & 1.00 & Sigma Chemicals Pty Ltd, Australia \\
\hline Ethylene glycol & AR & 1.00 & Chem-Supply Pty Ltd, Australia \\
\hline Magnesium sulphate & AR & 1.00 & Scharlan Pty Ltd, Australia \\
\hline Sodium bicarbonate & AR & 1.00 & Fresenius Medical Care Australia Pty Ltd \\
\hline Water & Reverse & Ultrapure & $\begin{array}{l}\text { Curtin University, Perth, Australia } \\
\text { (equipment from Ibis Technology Pty Ltd). }\end{array}$ \\
\hline
\end{tabular}


Table 4: List of the prepared synthetic brines (ppmv)

\begin{tabular}{|l|l|l|l|}
\hline Ions & Brine A & Brine B & Brine C \\
\hline $\mathrm{Ca}$ & 10 & 2000 & 1005 \\
\hline $\mathrm{Mg}$ & 8 & 32 & 20 \\
\hline $\mathrm{Fe}$ & 10 & 5.3 & 7.65 \\
\hline $\mathrm{Na}$ & 11 & 3215 & 1613 \\
\hline $\mathrm{K}$ & 4 & 100 & 52 \\
\hline $\mathrm{Ba}$ & - & 5.1 & 2.55 \\
\hline $\mathrm{Cl}$ & 34 & 7965 & 3999 \\
\hline $\mathrm{SO}_{4}$ & 32 & 126 & 79 \\
\hline $\mathrm{HCO}_{3}$ & 12 & 1100 & 556 \\
\hline $\mathrm{CO}_{3}$ & 16 & $<1$ & 8 \\
\hline $\mathrm{OH}^{2}$ & - & $<1$ & - \\
\hline
\end{tabular}

Table 5: The salt types and contents in Brine A and brine B (unit in g)

\begin{tabular}{|l|l|l|l|l|l|l|l|l|}
\hline & \multicolumn{6}{|l|}{ Salt content } \\
\hline Brine & $\mathrm{CaCl}_{2}$ & $\mathrm{MgSO}_{4}$ & $\mathrm{FeCl}_{2}$ & $\mathrm{KCl}$ & $\mathrm{NaHCO}_{3}$ & $\mathrm{NaCO}_{3} .10 \mathrm{H}_{2} \mathrm{O}$ & $\mathrm{NaCl}$ & $\mathrm{BaCl}_{2}$ \\
\hline A & 0.0366 & 0.0396 & 0.0227 & 0.0076 & 0.0165 & 0.0276 & - & - \\
\hline B & 7.33 & 0.158 & 0.012 & 0.194 & 1.515 & - & 7.120 & 0.00774 \\
\hline
\end{tabular}

Alkalinity of each brine solution was determined by putting $50 \mathrm{ml}$ of the brine solution into a $250 \mathrm{ml}$ beaker which was then stirred with a magnetic stirrer at $360 \mathrm{rpm}$. A $0.098 \mathrm{M} \mathrm{HCl}$ solution was titrated into the beaker till $\mathrm{pH}$ of 2 was attained. A $0.1 \mathrm{M} \mathrm{NaOH}$ solution was then titrated into the new solution till the $\mathrm{pH}$ value increased to 12 . The total alkalinity $\left(A_{T}^{0}\right)$ which is defined by Kaasa and Ostvold (1996) in Equation 8 was then calculated using equation 9. The point of inflection of the generated $\mathrm{HCl}$ and $\mathrm{NaOH}$ titration curves were then analysed with CurtiPot program to detect their end points.

$$
\begin{aligned}
& A_{T}^{0}=\left[\mathrm{Na}^{+}\right]+2\left[\mathrm{Ca}^{2+}\right]-\left[\mathrm{Cl}^{-}\right]-2\left[\mathrm{SO}_{4}^{2-}\right]=\left[\mathrm{HCO}_{3}^{-}\right]+2\left[\mathrm{CO}_{3}^{2-}\right]+\left[\mathrm{A}^{-}\right]+\left[\mathrm{OH}^{+}\right]-\left[\mathrm{H}^{-}\right] \\
& A_{T}^{0}=\frac{V_{\mathrm{HCl}}^{\text {tot }}[\mathrm{HCl}]-V_{\mathrm{NaOH}}^{A}[\mathrm{NaOH}]}{V^{0}}
\end{aligned}
$$


Where $A_{T}^{O}$ is the total alkalinity; $V^{0}$ is the volume of brine used; $V_{H C l}^{\text {tot }}$ is the total volume of $\mathrm{HCl}$ used; $V_{\mathrm{NaOH}}^{A}$ is the volume of $\mathrm{NaOH}$ at equivalence and $[G]$ is the concentration of solution G.

\subsubsection{Preparation of the Rich MEG Solutions}

Fresh MEG solution of 85 wt \% was prepared by mixing MEG of $83.55 \%$ v/v with deionised water of $16.45 \% \mathrm{v} / \mathrm{v}$. Three rich MEG solutions were then prepared by mixing the fresh MEG solution with each synthetic brine samples at $50 \% \mathrm{v} / \mathrm{v}$. The measurement of certainty for each solution was predicted by measuring its $\mathrm{pH}$ correction factor $\left(\mathrm{pH}_{\text {corrected }}\right)$ both at 22 ${ }^{\circ} \mathrm{C}$ and $80{ }^{\circ} \mathrm{C}$ by calibrating a pH electrode in standard IUPAC solutions of $\mathrm{pH} 4,7$ and 10 at temperature $\mathrm{T}$. The $\mathrm{pH}$ of a buffered solution $(0.05 \mathrm{~mol} / \mathrm{kg}$ potassium hydrogen phthalate $(\mathrm{KHPh})$ ) in MEG $85 \mathrm{wt} \%$ solution was then obtained at that same temperature as $p H_{\text {Measured }}$. Equation 10 as provided by Sandengen et al. (2007) was then used to calculate the reference value $\mathrm{pH}$ standard $\left(\mathrm{pH}_{\mathrm{RVS}}\right)$ for the solution and Equation 11 was finally used to calculated its correction factor.

$p H_{R V S}=4.00249+1.0907 w_{G}+0.9679 w_{G}^{2}+0.3430 z+0.03166 w_{G} z-0.8978 w_{G}^{2} z+$

$7.7821\left\{\ln \left(\frac{T}{\theta}\right)-z\right\}+9.8795 w_{G}^{3}\left\{\ln \left(\frac{T}{\theta}\right)-z\right\}$

$p H_{\text {corrected }}=\Delta p H_{M E G}+p H_{\text {measured }}$

Where $w_{G}$ is the MEG's wt. fraction in the salt free solvent; $z=T-\frac{\theta}{T} \quad$ and $\quad \theta=298.15$

\subsection{Experimentation}

Various laboratory experiments were conducted to study the pretreatment and reclamation sections of the industrial scale systems. For each study, a blank experiment was initially conducted followed by series of experiments with production chemicals. Differences in the generated data set were then considered for impact discussions. The pretreatment section was first studied and the recovered filtrates (liquors) were then reconcentrated to enable appropriate studies on reclamation section (Figure 1). These three stages are required for an industrial scale operation. 


\subsubsection{Experimental studies on Pretreatment section}

For each study, a blank baseline experiment was first conducted using a $50 \mathrm{ml}$ rich MEG 2 solution (Table 6) which was continuously stirred with a magnetic stirrer bar at $80{ }^{\circ} \mathrm{C}$ in a water bath with dropwise addition of $0.1 \mathrm{M} \mathrm{NaOH}$ till a $\mathrm{pH}$ of 9.6 was attained (Figure 1a). The scale formed was filtered out with an advantec glass fibre membrane filters grade GC50 that is rated to $<0.45 \mu \mathrm{m}$ through a funnel into a flask. A Sparmax vacuum pump with a 675 $\mathrm{mm} \mathrm{Hg}$ rating was then used to vacuum the whole system.

Table 6: The laboratory prepared rich MEG solutions for the study

\begin{tabular}{|l|l|}
\hline Rich MEG & Composition \\
\hline 1 & $50 \%$ v Brine A + 50 \% v MEG (85 wt \%) \\
\hline 2 & $50 \%$ v Brine B + 50 \% v MEG (85 wt \%) \\
\hline 3 & $50 \%$ v Brine C + 50 \% v MEG (85 wt \%) \\
\hline
\end{tabular}

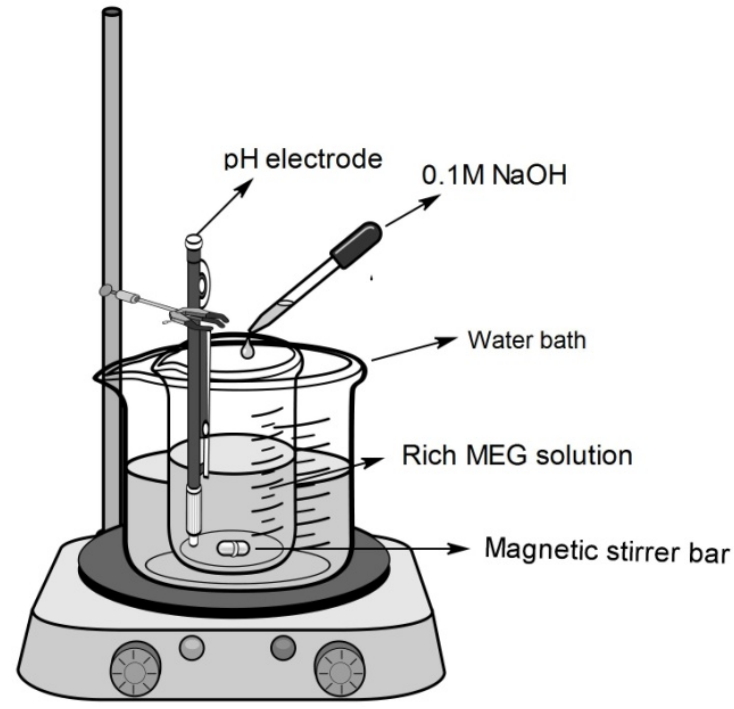

a. Pretreatment study

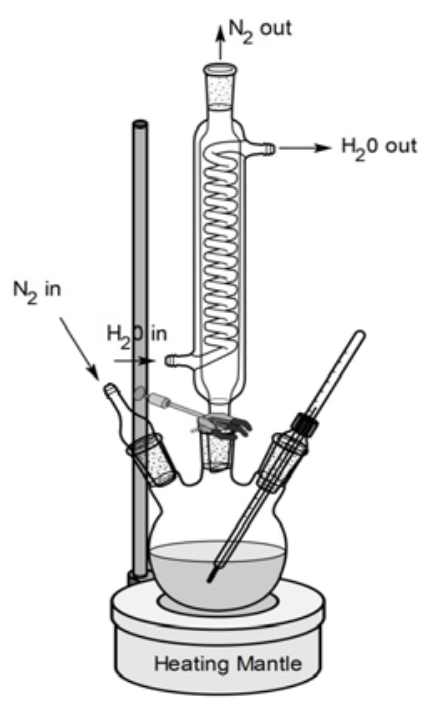

b. Reconcentration study. 


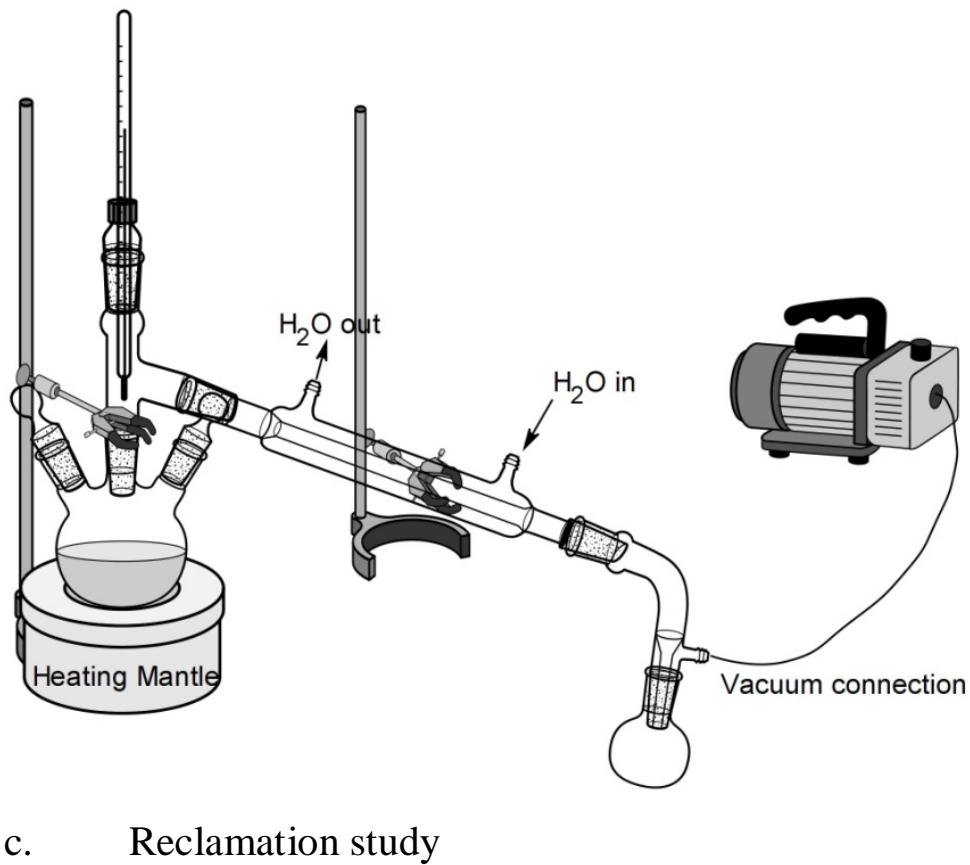

Figure 1: The experimental set-up for various sections of the study.

Each production chemical was then studied by repeating the same procedure but dosing the system with 250 ppmv of the inhibitor (either corrosion or scale, but not both) at a time at the $\mathrm{pH}$ of 9.6. The final set of experiments on pretreatment section were conducted by repeating the same procedure but $250 \mathrm{ppm}$ of each corrosion inhibitor, mixed with $250 \mathrm{ppm}$ of the scale inhibitor was added to the rich MEG solution at the $\mathrm{pH}$ of 9.6 in this test (Table 7). These dosage rates correspond with those at the upstream operations of $1.28 \mathrm{ml}$ for a corrosion inhibitor and $14 \mu \mathrm{l}$ for a scale inhibitor. Each experiment was repeated three times for data reproductibility and the recorded values were calculated using

$x=\frac{\sum_{i=1}^{N}\left(x_{i}\right)}{N}$

$x$ is the mean value, $x_{i}$ is generated / experimental values and $N$ is the number of samples. 
Table 7: Concentration of each inhibitor added to $50 \mathrm{ml}$ of rich MEG solution for studies on the pretreatment section $\left(\mathrm{pH}=9.6, \mathrm{~T}=80^{\circ} \mathrm{C}\right)$

\begin{tabular}{|l|l|l|l|l|}
\hline \multirow{2}{*}{ Expt run } & \multicolumn{5}{|c|}{ Additives (ppm) } \\
\cline { 2 - 5 } & C.P.C & D.P.C & B.D.H.C & A.M.T.P \\
\hline 1 (Blank) & 0 & 0 & 0 & 0 \\
\hline 2 & 250 & 0 & 0 & 0 \\
\hline 3 & 0 & 250 & 0 & 0 \\
\hline 4 & 0 & 0 & 250 & 0 \\
\hline 5 & 0 & 0 & 0 & 250 \\
\hline 6 & 250 & 0 & 0 & 250 \\
\hline 7 & 0 & 250 & & 250 \\
\hline 8 & 0 & 0 & 250 & 250 \\
\hline
\end{tabular}

\subsubsection{Experimental studies on Reclamation section}

Filtrates recovered from the pretreatment stage were reconcentrated and used for the study on reclamation section. $100 \mathrm{ml}$ of the filtrate was heated with an electric heating mantle in a three-neck round bottom flask at $115{ }^{\circ} \mathrm{C}$ for reconcentration. The system was refluxed for 48 hours with nitrogen gas passing at $0.5 \mathrm{ml} / \mathrm{min}$ via a gas sparging adaptor attached to the side neck and exiting through a graham type condenser attached to the middle neck (Figure $1 \mathrm{~b}$ ). The refluxed solution was distilled under ambient pressure at $107^{\circ} \mathrm{C}$ till no more liquid was left to carry over. The generated liquor was then subjected to vacuum distillation at $80 \mathrm{kPa}$ and $140{ }^{\circ} \mathrm{C}$ (Figure 1c). The vacuum distillation process was stopped after $50 \% \mathrm{v} / \mathrm{v}$ of the liquor had been flashed off. The remaining liquor inside the round bottom flask was cooled to room temperature and the scale deposits formed were separated by vacuum filtration and dried for 18 hours in an oven at $105{ }^{\circ} \mathrm{C}$ and weighed. The final liquor from this reconcentration process was then used as blank MEG solution for the reclamation section.

Like in the pretreatment stage, the experiments in the reclamation section were conducted on blank MEG solution and solutions with added inhibitors. In addition to the earlier prepared 250 ppmv production chemicals, 1000 ppmv of each production chemical was equally prepared for further studies (Table 8). Each experiment was repeated twice for data validation. 
Table 8: Concentration of each inhibitor added to $50 \mathrm{ml}$ of rich MEG solution for studies on the reclamation section $\left(\mathrm{T}=115{ }^{\circ} \mathrm{C}\right.$ and reflux time $\left.=48 \mathrm{~h}\right)$

\begin{tabular}{|l|l|l|l|l|}
\hline \multirow{2}{*}{ Expt. run } & \multicolumn{5}{|c|}{ Additives (ppm) } \\
\cline { 2 - 5 } & C.P.C & D.P.C & B.D.H.C & A.M.T.P \\
\hline 1 (Blank) & 0 & 0 & 0 & 0 \\
\hline 2 & 250 & 0 & 0 & 0 \\
\hline 3 & 0 & 250 & 0 & 0 \\
\hline 4 & 0 & 0 & 250 & 0 \\
\hline 5 & 0 & 0 & 0 & 250 \\
\hline 6 & 250 & 0 & 0 & 250 \\
\hline 7 & 0 & 250 & 0 & 250 \\
\hline 8 & 0 & 0 & 250 & 250 \\
\hline 9 & 1000 & 0 & 0 & 0 \\
\hline 10 & 0 & 1000 & 0 & 0 \\
\hline 11 & 0 & 0 & 1000 & 0 \\
\hline 12 & 0 & 0 & 0 & 1000 \\
\hline 13 & 1000 & 0 & 0 & 1000 \\
\hline 14 & 0 & 1000 & 0 & 1000 \\
\hline 15 & 0 & 0 & 1000 & 1000 \\
\hline
\end{tabular}

\subsection{FT-IR Spectrometer analysis of solid scales in rich MEG solutions.}

After each experiment, a Perkin Elmer Spectrum 100 FT-IR Spectrometer with a software package of version 6.3.4 was used to check for any degradation in the rich MEG solution. A $40 \mathrm{mg}$ sample was placed on the top plate detector window of the Fourier Transform Infrared Spectroscopy (FT-IR) after conducting a background scan and a spectra was then produced at wave number range of $650 \mathrm{~cm}^{-1}$ to $4000 \mathrm{~cm}^{-1}$. 


\section{$3 \quad$ RESULTS AND DISCUSSIONS}

The results generated both by the software and laboratory studies are presented in this section. Scaling index as predicted by ScaleSoftPitzer software for the pretreatment section was analysed and the associated corrosion problems on real MEG regeneration system were identified. The various data generated through the experimental studies were then presented and their implications on the large scale pretreatment and reclamation sections discussed. Moreover, impacts of some incomplete reactions from reconcentration section on reclamation section was identified and discussed. Finally, the overall implications of this study on industrial scale MEG regeneration process were presented.

\subsection{Software Prediction results on the pretreatment Section}

Results as generated by the ScaleSoftPitzer software on scaling index (S.I) for the synthetic brines solutions at $22{ }^{\circ} \mathrm{C}$ are presented in Table 9. It is observed that monovalent scales (such as $\mathrm{NaCl}$ ) were unlikely to form both in the synthetic brine; however, divalent scales would be produced. From the table, Brine A is not likely to produce scales at ambient conditions whereas; there is a higher likelihood of scale formation in Brines B and C. Also, there is an indication for Brine $\mathrm{B}$ to strongly form both $\mathrm{CaCO}_{3}$ and $\mathrm{BaSO}_{4}$ scales while brine $\mathrm{C}$ will mainly form $\mathrm{CaCO}_{3}$ scales but little of $\mathrm{BaSO}_{4}$ scales. This could be attributed to the dilution factor resulting from mixing Brines A with Brine B.

Table 9: Scaling Indices for synthetic brine solutions in the pretreatment section at $22{ }^{\circ} \mathrm{C}$

\begin{tabular}{|c|c|c|c|c|}
\hline \multirow[b]{2}{*}{ Solution } & \multirow[b]{2}{*}{ pH } & \multicolumn{3}{|c|}{ Scaling Index (S.I) } \\
\hline & & $\mathrm{CaCO}_{3}$ & $\mathrm{BaSO}_{4}$ & $\mathrm{FeCO}_{3}$ \\
\hline Brine $\mathrm{A}$ & 6.85 & -2.48 & - & - \\
\hline Brine $\mathrm{B}$ & 6.93 & 1.37 & 1.27 & - \\
\hline Brine C & 7.15 & 2.76 & 0.99 & - \\
\hline
\end{tabular}

Exactly the same scaling trend was observed for all rich MEG solutions both at ambient and high temperature conditions (Table 10). Rich MEG 1 is unlikely to produce scaling except for $\mathrm{FeCO}_{3}$ while rich MEG 2 and rich MEG 3 have high tendencies to form $\mathrm{CaCO}_{3}, \mathrm{BaSO}_{4}$ and $\mathrm{FeCO}_{3}$ scales with same trend of scale production of $\mathrm{CaCO}_{3}>\mathrm{FeCO}_{3}>\mathrm{BaSO}_{4}$. 
Noteworthy is the software's prediction on the production of $\mathrm{FeCO}_{3}$ scaling in all the rich MEG solutions whereas, this was not present in any of the neat synthetic brines. This shows that the dissolved salts which are in ionic forms will initiate corrosion in the MEG regeneration system with $\mathrm{FeCO}_{3}$ scaling as by-product. Also, it was observed from the same table that corrosion products increase with temperature which agrees with literatures (Esmaily et al, 2015; Hou et al, 2015). It should be noted however that ScaleSoftPitzer does not account for scaling of other divalent salts such as $\mathrm{MgSO}_{4}$. It is therefore possible that magnesium based divalent salts might be produced since $\mathrm{MgSO}_{4}$ was also used for the preparation of Brines A and B.

Table 10: S.I. values for rich MEG solutions in the pretreatment section at $22{ }^{\circ} \mathrm{C}$ and $80{ }^{\circ} \mathrm{C}$

\begin{tabular}{|c|c|c|c|c|}
\hline \multirow{2}{*}{ Solution } & \multirow{2}{*}{$\mathbf{p H}$} & \multicolumn{3}{c|}{ Scaling Index (S.I) } \\
\cline { 3 - 5 } & \multicolumn{5}{|c|}{$\mathbf{C a C O}_{3}$} & BaSO $_{4}$ & FeCO $_{3}$ \\
\hline \multicolumn{2}{|c|}{$\mathbf{T}={ }^{\circ} \mathbf{C}$} \\
\hline Rich MEG 1 & 6.40 & -1.68 & - & 0.04 \\
\hline Rich MEG 2 & 6.60 & 1.88 & 1.52 & 1.36 \\
\hline Rich MEG 3 & 6.65 & 2.53 & 1.83 & 2.21 \\
\hline & & $\mathbf{T}=\mathbf{8 0}^{\circ} \mathbf{C}$ & 1.68 \\
\hline Rich MEG 1 & 9.62 & - & - & 3.28 \\
\hline Rich MEG 2 & 9.65 & 3.97 & 1.52 & 2.90 \\
\hline Rich MEG 3 & 9.64 & 3.34 & 1.83 & \\
\hline
\end{tabular}

\subsection{Scaling of rich MEG solutions at pretreatment}

Sizes of divalent salts range from $10 \mu \mathrm{m}$ to $25 \mu \mathrm{m}$ (Baraka et al., 2012); hence, the $0.45 \mu \mathrm{m}$ filter used for this study is appropriate. The cake samples from the filtration process were weighed as presented in Table 11. Total Dissolved Solid (TDS) results from the table shows the scaling trend produced by the experimental study to be in the order of rich MEG $2>$ rich MEG $3>$ rich MEG 1. This trend agrees with the ScaleSoftPitzer software prediction as observed in Table 10 and is also justified by the salt contents in each solution as shown in Table 12. 
Table 11: Amount of scaling generated in the pretreatment section at $80{ }^{\circ} \mathrm{C}$ and $50 \mathrm{ml}$

\begin{tabular}{|l|l|l|l|}
\hline Solution & pH & Scale Weight (g) & T.D.S (mg/L) \\
\hline Rich MEG 1 & 9.62 & 0.0002 & 4 \\
\hline Rich MEG 2 & 9.65 & 0.0093 & 186 \\
\hline Rich MEG 3 & 9.64 & 0.005 & 100 \\
\hline
\end{tabular}

Brine $B$ has the highest value of total alkalinity while that of Brine $C$ was the lowest, this is attributed to the higher concentrations of the active salts $\left(\mathrm{NaCl}, \mathrm{NaHCO}_{3}\right.$, etc.) in brine $\mathrm{B}$ compared to brine $\mathrm{C}$ that was a mixture of equal volumes of brines $\mathrm{A}$ and $\mathrm{B}$. The lower alkalinity value of brine $\mathrm{C}$ compared to brine A meant that the concentration of $\mathrm{NaHCO}_{3}$ (the main salt contributing to alkalinity) had been diluted during the mixing of both brine solutions.

Table 12: The total alkalinity values for the brines (the volumes $\left(V_{N a O H}^{A}\right.$ and $\left.V_{H C l}^{t o t}\right)$ are measured in $\mathrm{ml}$, concentrations $([\mathrm{HCl}]$ and $[\mathrm{NaOH}]$ ) are measured in $\mathrm{M}$ and total alkalinity $\left(A_{T}^{O}\right)$ is measured in $\mathrm{mmol} / \mathrm{L}$

\begin{tabular}{|c|c|c|c|}
\hline Measured item & Brine A & Brine B & Brine C \\
\hline $\mathrm{V}_{\mathrm{HCl}}^{\mathrm{tot}}$ & 18.40 & 21.60 & 13.10 \\
\hline$[\mathrm{HCl}]$ & 0.098 & 0.098 & 0.098 \\
\hline $\mathrm{V}_{\mathrm{NaOH}}^{\mathrm{A}}$ & 7.24 & 6.38 & 3.83 \\
\hline$[\mathrm{NaOH}]$ & 0.1 & 0.1 & 0.1 \\
\hline $\mathrm{V}^{0}$ & 50.0 & 50 & 50 \\
\hline $\mathrm{A}_{\mathrm{T}}^{\mathrm{O}}$ & 21.58 & 29.58 & 18.02 \\
\hline
\end{tabular}

Further observations of the total alkalinity plots showed brine B and brine $\mathrm{C}$ having almost the same trend whereas, that of brine A was slightly different (Figure 2). It can be seen that the line which started at $\mathrm{pH}$ of almost 7 in all the plots dropped very fast to $0.37 \mathrm{ml}$ in brine $\mathrm{A}$ but remained high in brines $\mathrm{B}$ and $\mathrm{C}$ at $7.2 \mathrm{ml}$ and $4.6 \mathrm{ml}$ respectively before dropping fast. This matched up well with the compositional make up of brine A and B respectively as presence of anionic species in brine A which contributed to alkalinity (in accordance to equation 8) are minimal in contrast to that of brine B. 


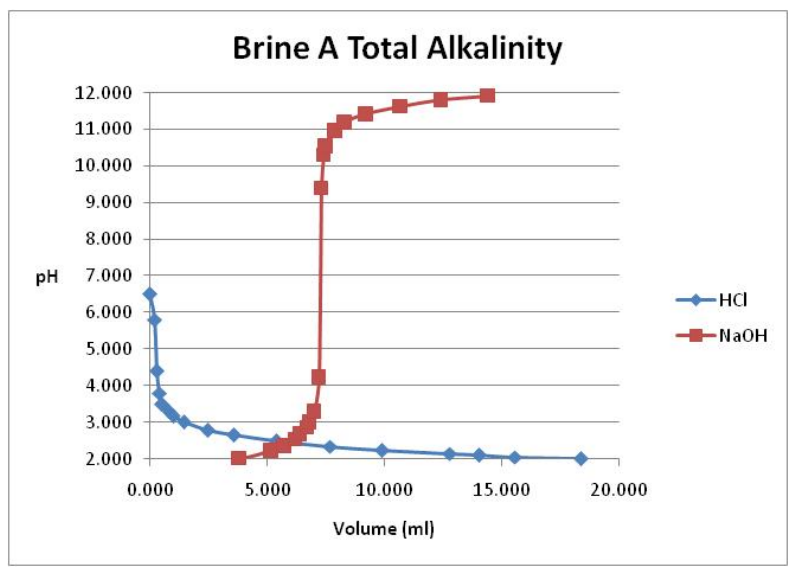

a.) Brine $\mathrm{A}$

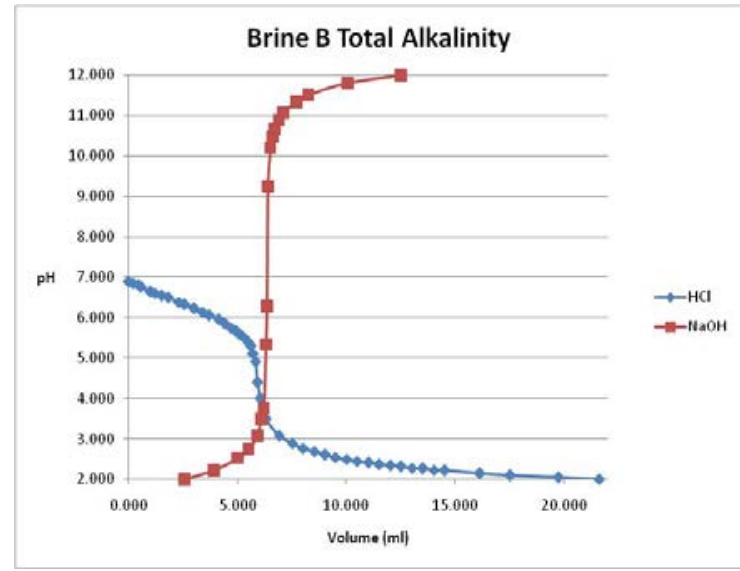

b.) Brine $\mathrm{B}$

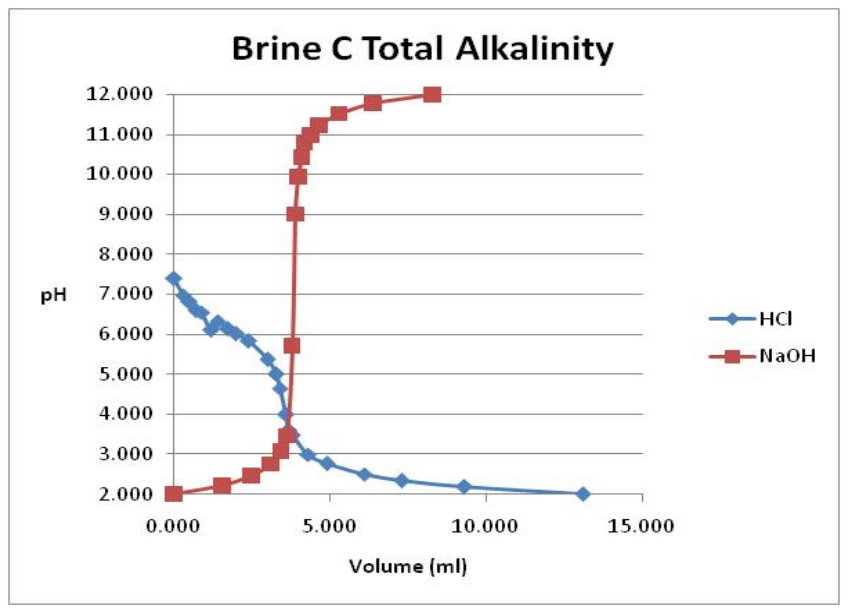

c.) Brine $\mathrm{C}$

Figure 2: Total alkalinity plots for synthetic brine solutions $(0.098 \mathrm{M} \mathrm{HCl}$ and $0.1 \mathrm{M} \mathrm{NaOH})$

The point of inflection as generated by CurTiPot software for brine A and brine B are presented in Figure 3. Brine A had its point of inflection at $7.2442 \mathrm{ml}$ and $\mathrm{pH}$ of 6.581 while that of brine B was at $6.3781 \mathrm{ml}$ and $\mathrm{pH}$ of 7.916. Since brines A and B represent the condensed water and formation water respectively, then, the scale formation will be more prevalent when formation water is mainly present in the regeneration section compared to condensed water. This is also in good agreement with the software prediction that rich MEG 1 solution would have a medium to high risk of only $\mathrm{FeCO}_{3}$ precipitation and scaling compared to the rich MEG 2 which has high risk of $\mathrm{CaCO}_{3}$ and $\mathrm{FeCO}_{3}$ precipitation and scaling, and medium risk of $\mathrm{BaSO}_{4}$ precipitation and scaling. 


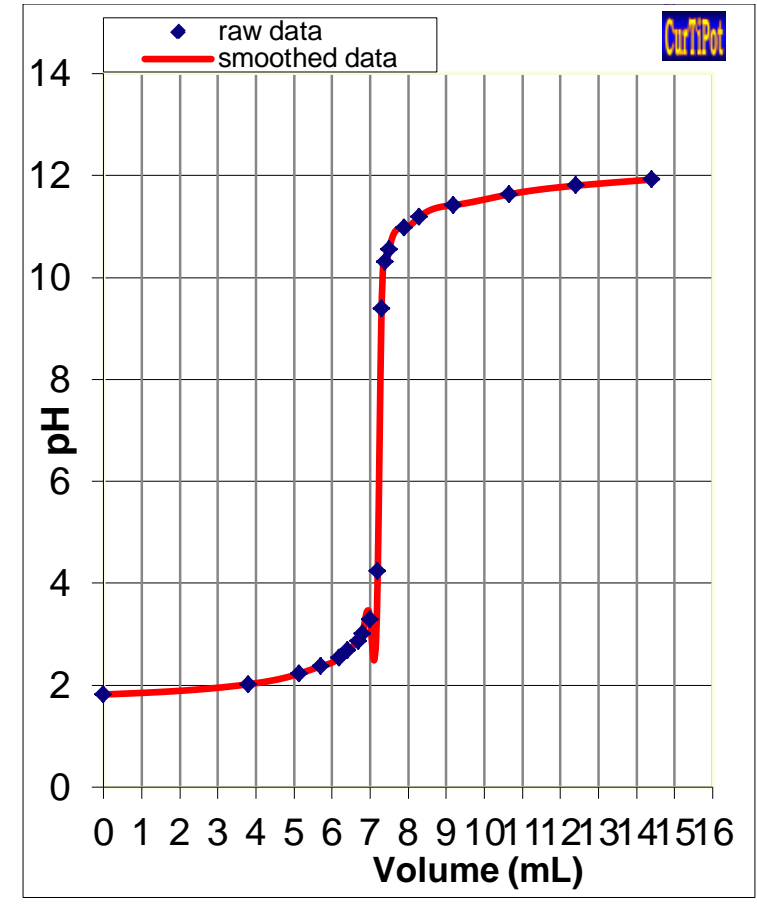

Brine A

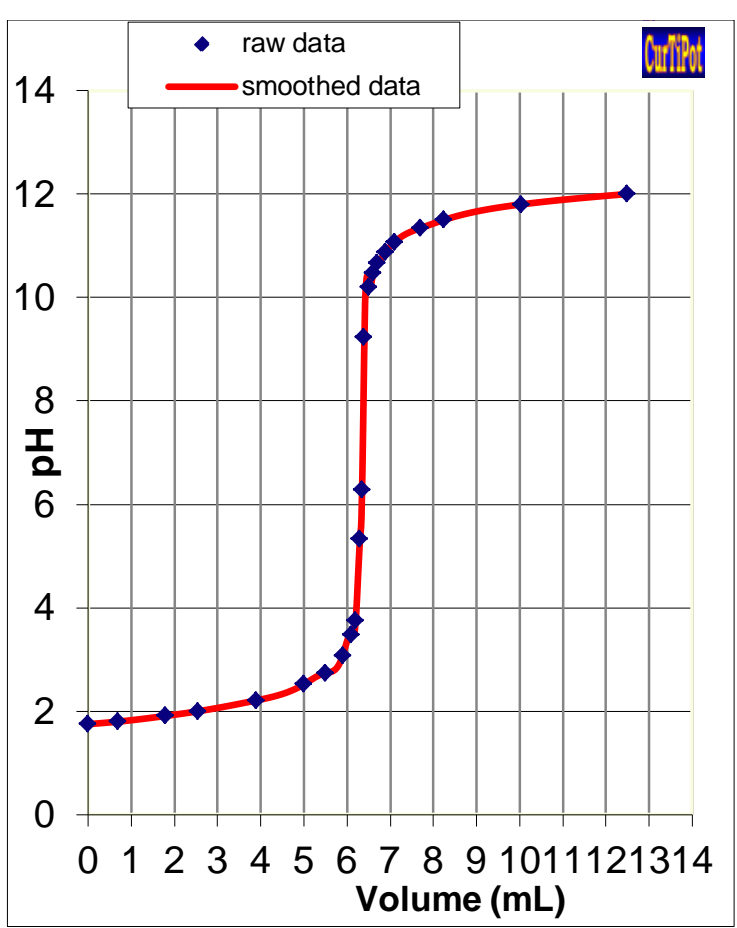

Brine B

Figure 3: The CurTiPot end point results for brine A and B solutions

\subsection{Effects of Production Chemicals on the Regeneration System}

The results in this section are only compared with those generated on rich MEG 2 in section

3.2 since only rich MEG 2 from the previous section was reconcentrated for further studies.

\subsubsection{Effects on pretreatment section}

Total amount of scale generated due to the presence of production chemicals are presented in Table 13 while the specific amounta contributed by the inhibitors with the corresponding TDS were calculated using equations 13 and 14 respectively as presented in Table 14 . It is seen in Table 14 that all the production chemicals significantly induce the production and precipitation of divalent salts

$A S_{P}=A S_{T}-A S_{M E G 2}$

$T D S_{P}=T D S_{T}-T D S_{M E G ~}$

$A S_{P}$ and $T D S_{P}$ are the amounts of scale and TDS generated by the specific production chemical(s), $A S_{T}$ and $T D S_{T}$ are the amount of scales and TDS given in Table 13 for each experimental run while $A S_{M E G 2}$ and $T D S_{M E G 2}$ are the amount of scale and TDS generated 
by MEG 2 in the absence of the production chemicals (from Table 11, these are $9.3 \mathrm{mg}$ and $186 \mathrm{mg} / \mathrm{L}$ respectively).

Addition of $0.1 \mathrm{M} \mathrm{NaOH}$ during the experimentation ensured a minimal contribution of monovalent salts to the scale production due to its low concentration (Anderko et al., 2010). Likewise, operating at $80{ }^{\circ} \mathrm{C}$ with addition of the $\mathrm{NaOH}$ until the $\mathrm{pH}$ of 9.6 shifted the reaction to right thereby causing the deposition of calcite solids (Equation 15) and other divalent salts (Sandengen, 2006).

$\mathrm{Ca}^{2+}(a q)+\mathrm{CO}_{2}(a q)+2 \mathrm{OH}^{-} \leftrightarrow \mathrm{CaCO}_{3}(s)+\mathrm{H}_{2} \mathrm{O}(a q)$

Table 13: Amount of the generated scaling at pretreatment section under the influence of production chemicals at $80^{\circ} \mathrm{C}$ and $\mathrm{pH}$ of $9.6(\mathrm{MEG} 2$ solution $=50 \mathrm{ml})$.

\begin{tabular}{|c|c|c|c|c|c|c|}
\hline \multirow[t]{2}{*}{ Expt. run } & \multicolumn{4}{|c|}{ Additives } & \multirow{2}{*}{$\begin{array}{l}\text { Produced } \\
\text { scale (mg) }\end{array}$} & \multirow{2}{*}{$\begin{array}{l}\text { T.D.S } \\
\text { (mg/L) }\end{array}$} \\
\hline & C.P.C & D.P.C & B.D.HC & A.T.M.P & & \\
\hline 1 & 250 & 0 & 0 & 0 & 25.7 & 514 \\
\hline 2 & 0 & 250 & 0 & 0 & 26.4 & 528 \\
\hline 3 & 0 & 0 & 250 & 0 & 26.7 & 534 \\
\hline 4 & 0 & 0 & 0 & 250 & 33.7 & 674 \\
\hline 5 & 250 & 0 & 0 & 250 & 31.3 & 626 \\
\hline 6 & 0 & 250 & 0 & 250 & 31.8 & 636 \\
\hline 7 & 0 & 0 & 250 & 250 & 35 & 761 \\
\hline
\end{tabular}

Table 14: Amount of the scaling contributed by the production chemicals alone at pretreatment section $\left(\mathrm{T}=80^{\circ} \mathrm{C} ; \mathrm{pH}=9.6\right.$ and MEG 2 solution $\left.=50 \mathrm{ml}\right)$

\begin{tabular}{|c|c|c|c|c|c|c|c|}
\hline Experimental run & 1 & 2 & 3 & 4 & 5 & 6 & 7 \\
\hline Produced scale (mg) & 16.4 & 17.1 & 17.4 & 24.4 & 22.0 & 22.5 & 25.7 \\
\hline T.D.S (mg/L) & 328 & 342 & 348 & 488 & 440 & 450 & 575 \\
\hline
\end{tabular}




\subsubsection{Effects on reclamation section}

According to Nazzer and Keogh (2006), $90 \%$ of the solids precipitating at this step are at least $50 \mu \mathrm{m}$ in size due to agglomeration; therefore, the $0.45 \mu \mathrm{m}$ filter employed in this study was adequate to totally isolate the generated solids. The total amount of generated scales from this study is presented in Table 15 while Table 16 gives the actual contributions from the production chemicals. Since the blank studies were conducted on $250 \mathrm{ppm}$ only, Table 16 was therefore limited to the difference in scaling amounts at the same concentration while further discussion on the 1000 ppm was based on results from Table 15.

Table 15: The liquor and scaling amount generated at reclamation section under the influence of production chemicals

\begin{tabular}{|c|c|c|c|c|c|c|c|}
\hline \multirow[t]{2}{*}{ Expt. run } & \multicolumn{4}{|c|}{ Additives } & \multirow{2}{*}{$\begin{array}{l}\text { Weight } \\
\text { (mg) }\end{array}$} & \multirow{2}{*}{$\begin{array}{l}\text { Liquor } \\
\text { Vol. (ml) }\end{array}$} & \multirow{2}{*}{$\begin{array}{l}\text { T.D.S } \\
\text { (mg/L) }\end{array}$} \\
\hline & C.P.C & D.P.C & B.D.H.C & A.T.M.P & & & \\
\hline Blank & 0 & 0 & 0 & 0 & 9.3 & 19 & 489.47 \\
\hline 1 & 250 & 0 & 0 & 0 & 15.5 & 15 & 1033.33 \\
\hline 2 & 0 & 250 & 0 & 0 & 16.1 & 15.5 & 1038.71 \\
\hline 3 & 0 & 0 & 250 & 0 & 17.5 & 15 & 1166.67 \\
\hline 4 & 0 & 0 & 0 & 250 & 35.7 & 14 & 2550.00 \\
\hline 5 & 250 & 0 & 0 & 250 & 30.4 & 17 & 1790.31 \\
\hline 6 & 0 & 250 & 0 & 250 & 24.49 & 13.5 & 1851.85 \\
\hline 7 & 0 & 0 & 250 & 250 & 19.7 & 16 & 1231.25 \\
\hline 8 & 1000 & 0 & 0 & 0 & 20.6 & 16 & 1287.50 \\
\hline 9 & 0 & 1000 & 0 & 0 & 20.5 & 16.5 & 1242.42 \\
\hline 10 & 0 & 0 & 1000 & 0 & 23.3 & 11.75 & 1982.98 \\
\hline 11 & 0 & 0 & 0 & 1000 & 68.7 & 16.5 & 4163.64 \\
\hline 12 & 1000 & 0 & 0 & 1000 & 62.4 & 23 & 2713.04 \\
\hline 13 & 0 & 1000 & 0 & 1000 & 38.4 & 15 & 2560.51 \\
\hline 14 & 0 & 0 & 1000 & 1000 & 85.6 & 14 & 6114.28 \\
\hline
\end{tabular}

Table 16 shows that production chemicals also contribute to scale generation at the reclamation section like in the pretreatment section. Comparison between Tables 14 and 16 showed that for the same concentrations of production chemicals, more amounts of scaling 
were generated in pretreatment section than in the reclamation section. This is because the divalent salts that are responsible for the scaling in the pretreatment section are heavier compared to the monovalent salts that are responsible for scaling in the reclamation section. In addition, monovalent salts are more soluble comparatively which makes them more difficult to precipitate (Memon et al, 2014; Kobayashi et al, 2014).

Table 16: Specific contributions of production chemicals to scaling at reclamation section

\begin{tabular}{|c|c|c|c|c|c|c|c|}
\hline Experimental run & 1 & 2 & 3 & 4 & 5 & 6 & 7 \\
\hline Scale amount (mg) & 6.2 & 6.8 & 8.2 & 26.4 & 21.1 & 15.19 & 10.4 \\
\hline T.D.S (mg/L) & 543.86 & 549.24 & 667.2 & 2060.53 & 1300.84 & 1362.38 & 741.78 \\
\hline
\end{tabular}

\subsection{Implications of this Study on MEG Regeneration Systems}

\subsubsection{General Impacts}

It is necessary for production chemicals to be applied in pipelines during oil and gas production; this study however has discovered that they ultimately influence salt production during MEG regeneration process. The resulting salts will cause additional salt loading on the regeneration system and may as well dissociate to cause scaling, corrosion and other negative impacts. These problems may ultimately results into emulsions, foaming and gunking in the regeneration plant; thus, causing separation problems, tripping of process equipment and contaminations in the lean storage tank (Halvorsen et al., 2009; Harrington et al., 2011).

Figure 4 shows that the scale inhibitor specifically initiated scale production more than corrosion inhibitors. This could be true considering that A.T.M.P. has great possibilities to produce both the divalent and monovalent salts when dissociated compared with corrosion inhibitors that are weaker due to their non-polar ends. Also, A.T.M.P has a lesser hydration ability due to the relatively stable chemical structure compared to the corrosion inhibitors which have charged highly electronegative ions. These charged ions enhance hydration resulting in reduced precipitation and scaling effects. As such, the more ionic nature of the corrosion inhibitor molecules due to electronegativity enable them to dissolve more easily in aqueous solutions compared to A.T.M.P molecules that are less ionic and less soluble. Consequently, A.T.M.P. precipitates more salts in solutions to produce more scaling. 


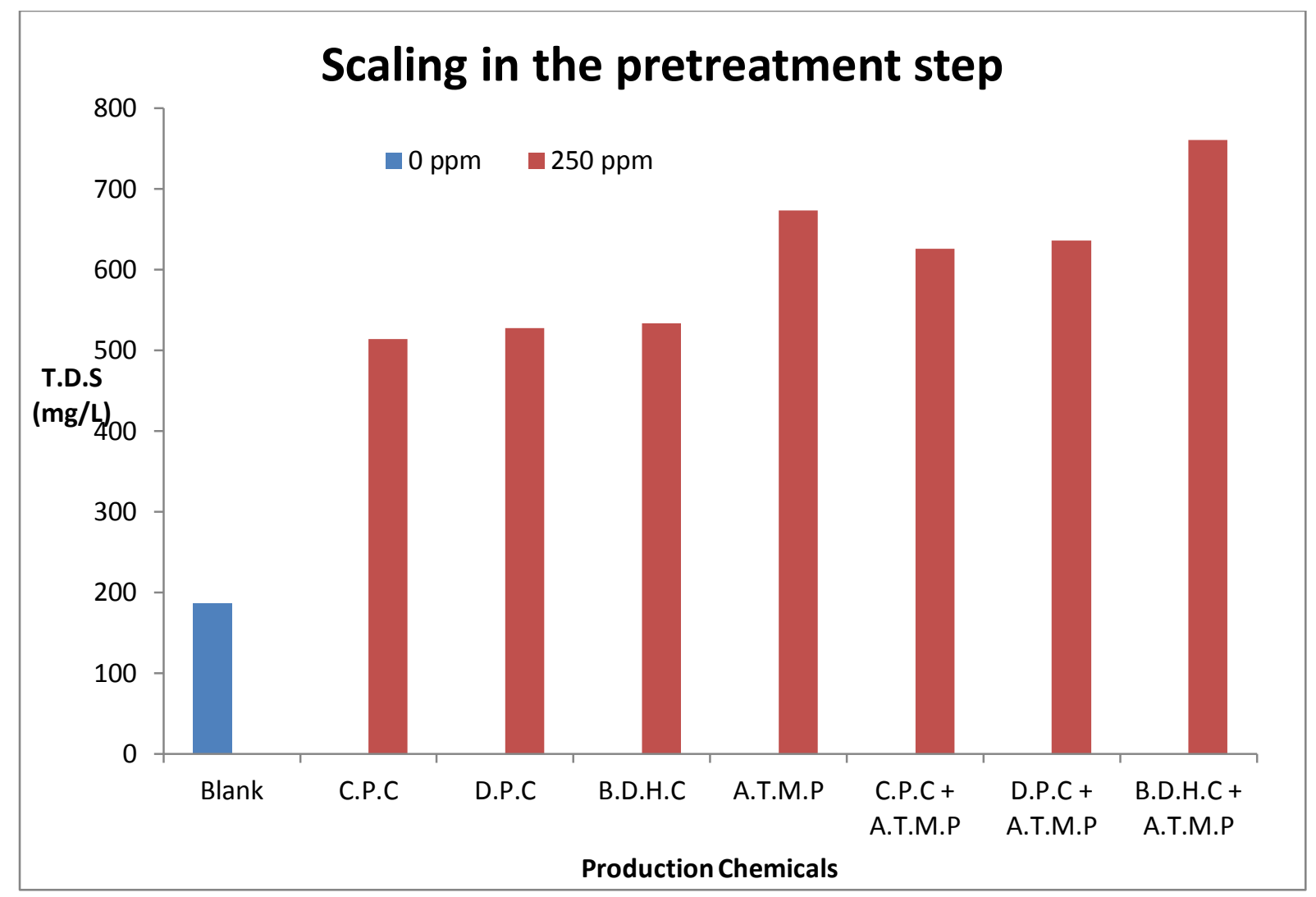

Figure 4: Graphical representation of pretreatment scaling with production chemicals.

B.D.H.C generated the highest amount of scaling amongst the corrosion inhibitors at all concentrations; even, when they were mixed with the scale inhibitor (Table 16). This may indicates the significant influence of alkyl length on the scale production considering that B.D.H.C has the longest amongst the three corrosion inhibitors. Increase in alkyl chain of a chemical increases its viscosity which then reduces its affinity for water through decreased reaction efficiency and increased interfacial tension (So and Lodge, 2015; Zhu and Lei, 2015). The reduced affinity of B.D.H.C for water then allows precipitation of more salts that dissociate to produce more scalings. It was further observed that C.P.C and D.P.C that belong to same family exhibited similar trends which might be as a result of their common active functional groups that enabled them to form N--H and $\mathrm{H}--\mathrm{Cl}$ bonds (Obanijesu et al, 2014b).

Further studies showed that the amount of generated scaling increased with increase in concentration of individual production chemical (Figure 5). This should be due to increase in available salt molecules. 


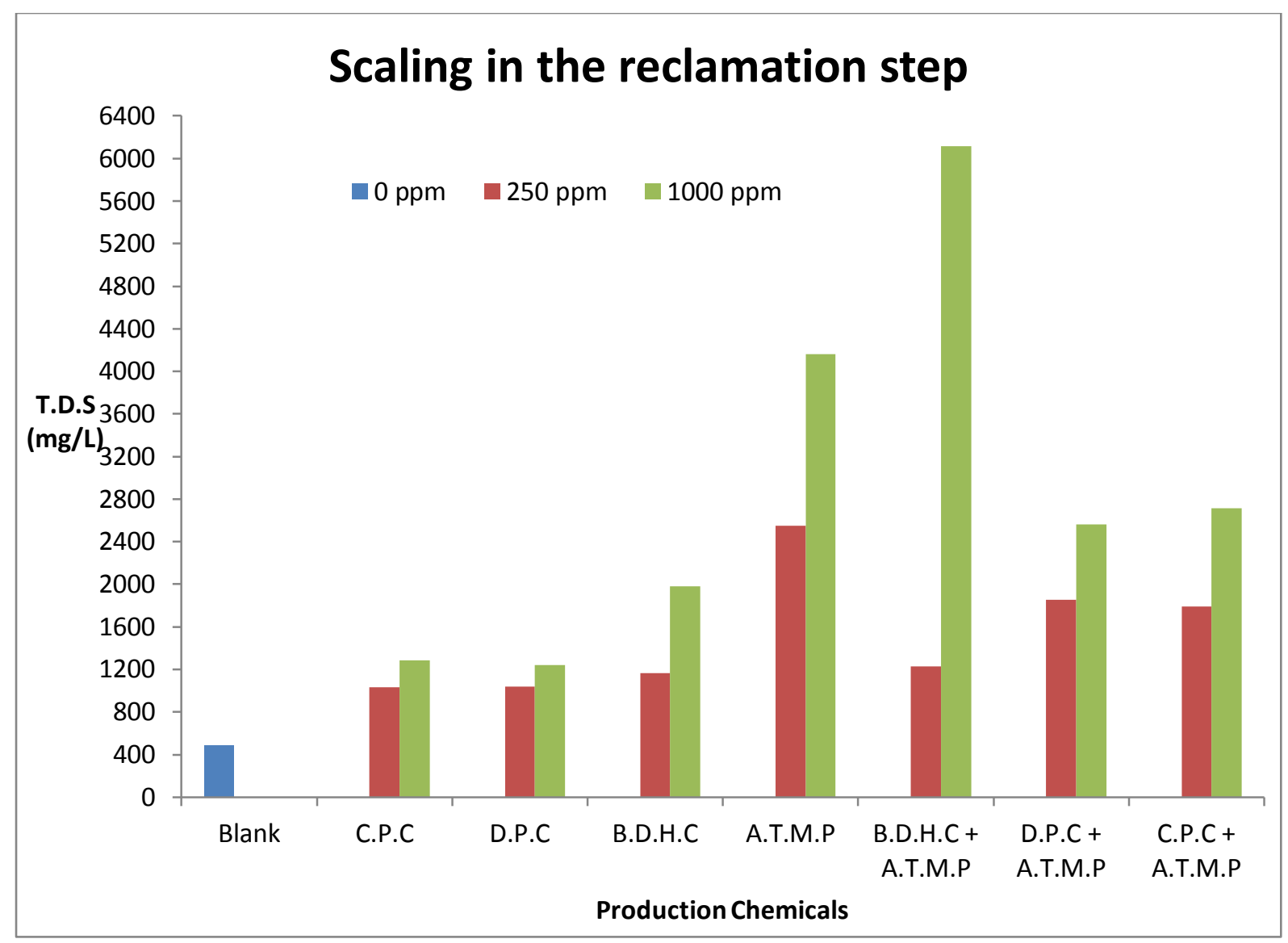

Figure 5: Impact of concentration on amount of generated scaling.

\subsubsection{Influence of reconcentration section on the reclamation section}

Comparing Tables 14 to Table 16 revealed that the TDS values for same concentrations from reclamation section are higher than those of pretreatment section. This is due to the quantity of available liquor for the salt solution in each section. From this study, while $50 \mathrm{ml}$ solvent was available for each solute in the pretreatment section, the reclamation section had between $13.5 \mathrm{ml}$ and $19 \mathrm{ml}$ available due to the loss of solvents that was boiled off at the reconcentration stage (Table 15). This may practically be a major issue to a real-life MEG regeneration process since the reconcentration section is in-between the pretreatment and reclamation sections and could result in a lot of problems to the entire system with the related financial consequences. The reconcentration section which involves operating at high temperatures will result in thermal degradation problems with exposure to air or oxygen to imminently attack the material(s) of construction. Other degradation/decomposition products include carboxylic, glycolic and formic acids (Rossiter et al., 1983; Psarrou et.al., 2011) that are of safety risk to the personnel and poisonous to the environment. Rossiter et al (1983) further reported that heating MEG in a copper material caused severe degradation and 
greatest amount of formic acid in aluminium materials. Meanwhile, pipeline industry use copper and aluminium alloys in their systems since they could not afford pure stainless steel due to cost implications. By extension, both the reconcentration and reclamation sections are subject to corrosion because the alloyed metals used for construction will corrode at the reconcentration section while the additional salt loading at the reclamation section will accelerate the corrosion.

\subsubsection{Scale and acid productions at the reclamation section}

Presence of scale inhibitor in reclamation section was investigated by comparing the FT-IR spectra from (rich MEG 2 + A.T.M.P.) to that of neat A.T.M.P. The two generated results were then super-imposed for observation in the closeness of their peaks. Figure 6 shows the peak of $\mathrm{P}=\mathrm{O}$ bond in the neat A.T.M.P. spectra to be at $1190 \mathrm{~cm}^{-1}$ compared to that of the solid scales spectra that is at $1145 \mathrm{~cm}^{-1}$. The lesser peak intensities suggested presence of A.T.M.P. in the solid scales recovered from the reclamation stage. This small quantity that would have come from the reconcentration liquor clearly indicates that the scale inhibitors used during normal pipeline operations somehow get into regeneration system; and that they are never completely boiled off during the reconcentration and reclamation steps. This outcome will inadvertently produce more salts that may dissociate to create more problems in the system. The huge amount of scaling obtained at the reclamation section of this study confirmed this result and may suggest a possibility for the divalent ions that were not precipitated out during pretreatment to form more solids in the presence of the scale inhibitor. 


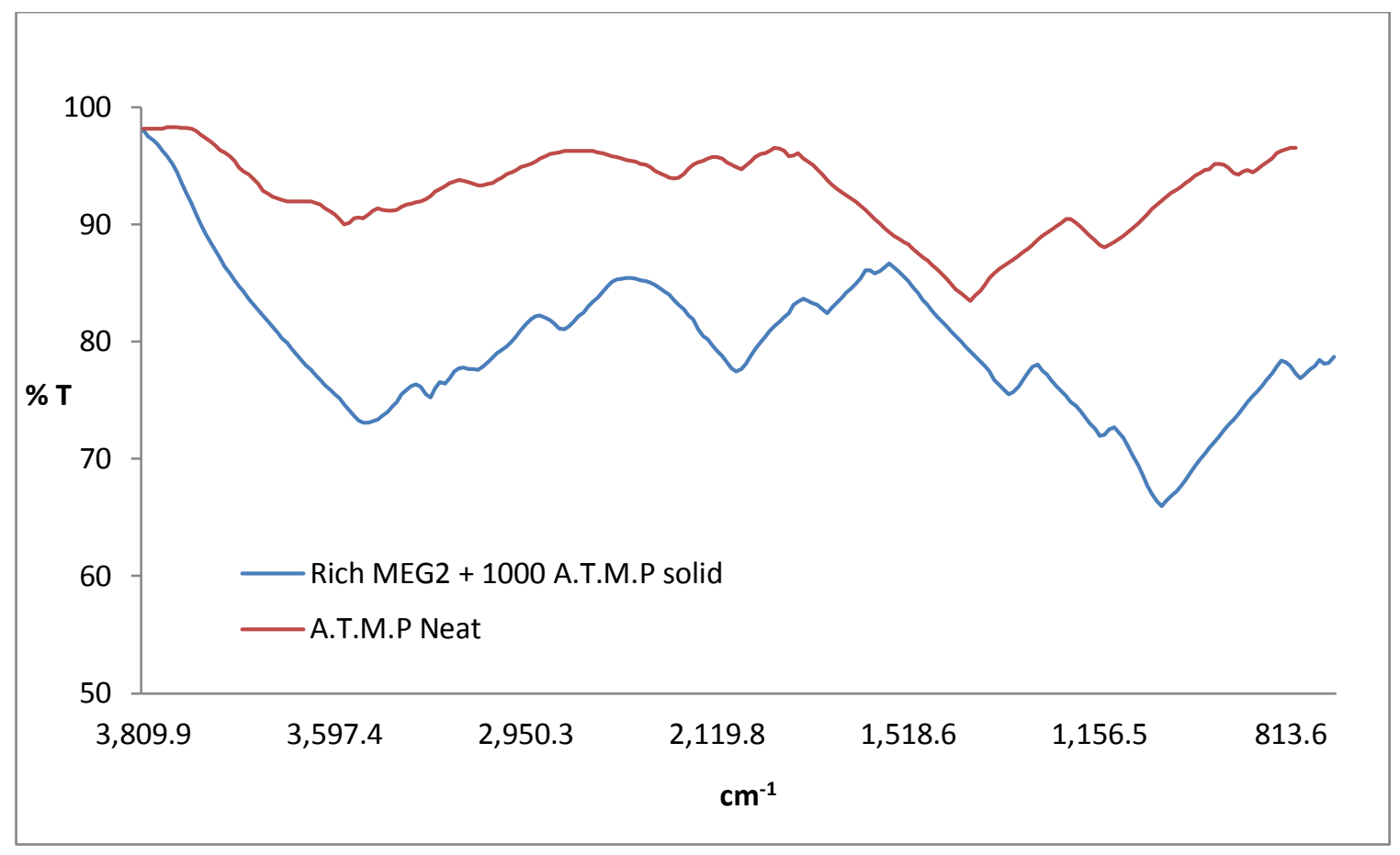

Figure 6: Super-imposed FT-IR spectra for (MEG 2 + A.M.T.P) and neat A.M.T.P solutions at the reclamation section (rich MEG $2=50 \mathrm{ml}$, A.T.M.P = $1000 \mathrm{ppm}$ )

Finally, the FT-IR spectra of the reconcentrated solution before reflux was further compared to that obtained after the 48 hours refluxing. This was to investigate a possibility of acid production at the reclamation section since their presence would add to scale productions. The presence of acid(s) would have been characterised on the FT-IR spectrophotometer by a sharp peak at approximately $1700 \mathrm{~cm}^{-1}$ due to the stretching of carbonyl $(\mathrm{C}=\mathrm{O})$ group; however, Figure 7 shows otherwise. The suggested absence of degradation products may be attributed to the inert atmosphere applied during the refluxing; thus, the scaling obtained at the reclamation section during the experiments was not influenced by any other products. 


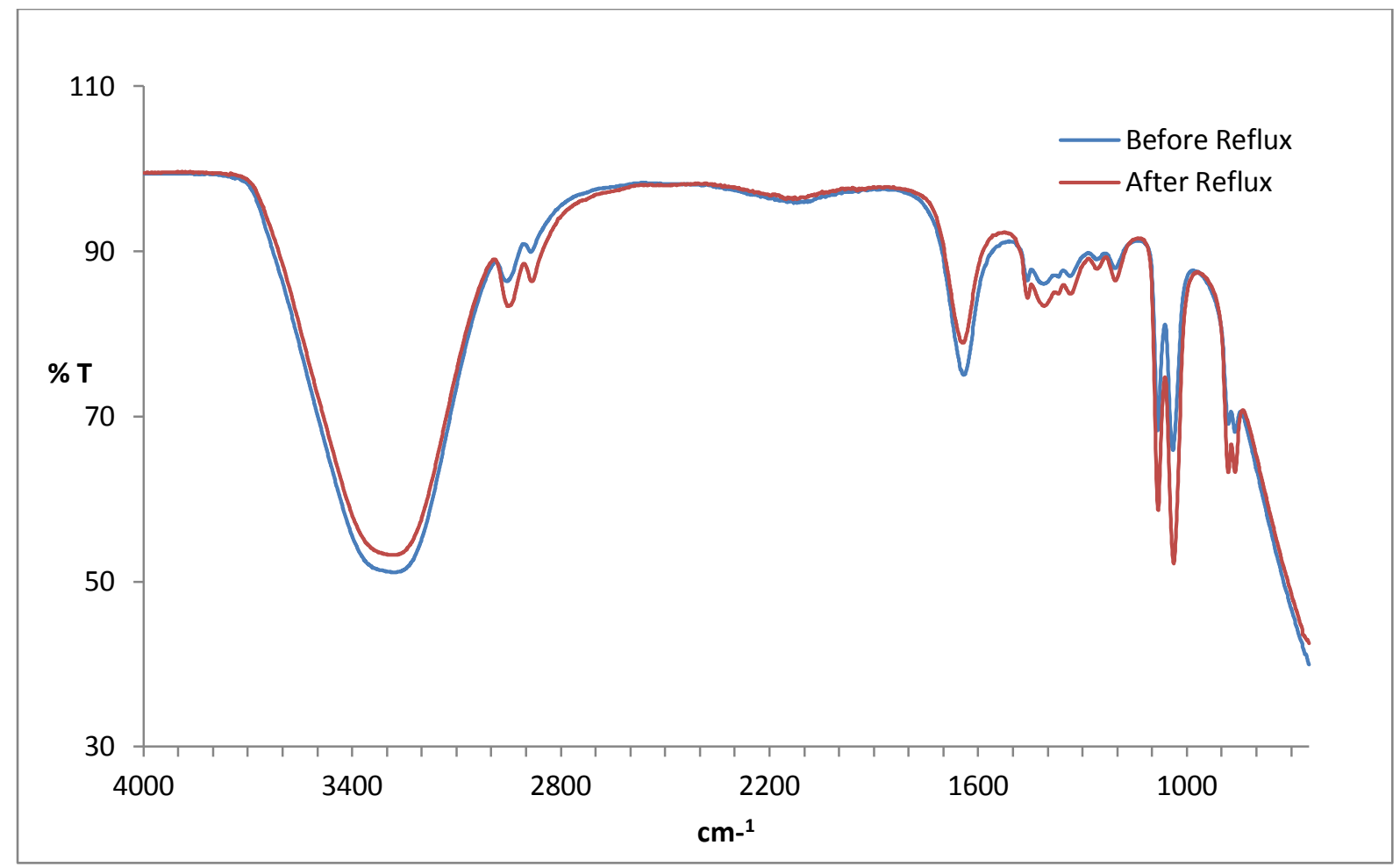

Figure 7: The FT-IR spectra of reconcentration solution before and after 48 hours reflux. 


\section{CONCLUSION}

This study establishes the interactions between production chemicals used in pipelines during oil and gas transportation. This ultimately promotes the production of monovalent and divalent salts in MEG regeneration plants. The resulting salts dissociate to form scaling, degradation of the recovered MEG and corrosion of the system which can ultimately impact on safety of the operation, personnel and environment. The corrosion would affect the system's shelf-life while the MEG degradation would impact on the operating cost.

The study further revealed that scale inhibitors have more potential to contribute to scaling problem compared to corrosion inhibitors, and that the amount of scale formation increases with concentration. This was attributed to the available bonding types that affect the chemicals' hydration ability. It was observed that B.D.H.C. was more severed compared to C.P.C and D.P.C due to its longer alkyl length that affects its viscosity and reactivity with ultimate impacts on its affinity for water. Mixing of scale and corrosion inhibitors that represents the real-life situation showed a more severe situation where salt precipitation and scaling are aggravated. Thus, the pipeline industry may need to find means of minimizing the possible molecular interactions between the corrosion inhibitors and scale inhibitors either by dilution or any other possible techniques.

Conclusively, the industry needs to intensively investigate means of managing the additional salt loading through research and development. This will assist in solving most of these problems encountered and ultimately improve on system safety and the related cost implications. 


\section{Nomenclature}

$\begin{array}{ll}\text { MEG } & \text { Ethylene glycol } \\ \text { wt } & \text { Weight } \\ \mathrm{m} & \text { Molality } \\ \text { ppm } & \text { parts per million } \\ \text { C.I } & \text { Corrosion inhibitor } \\ \text { S.I } & \text { Scaling Index } \\ \text { C.P.C } & \text { Cetylpryridinium Chloride } \\ \text { D.P.C } & \text { Docetylpyridinium Chloride } \\ \text { B.D.H.C } & \text { Benzyl dimethyl hexadecylammonium chloride } \\ \text { A.M.T.P } & \text { Aminotris (methylphosphonic acid) } \\ \text { CaCO } & \text { Calcium Carbonate } \\ \text { BaSO }_{4} & \text { Barium Sulphate } \\ \text { NaCl }_{\text {Mg(OH) }} & \text { Sodium Chloride } \\ \text { MgSO }_{4} & \text { Magnesium Hydroxide } \\ \text { FeCO }_{3} & \text { Magnesium Sulphate } \\ \text { FTIR }_{\text {V/v }} & \text { Fourier Transform Infrared Spectroscopy } \\ \text { T.D.S }_{\text {XRF }} & \text { Volume on volume } \\ & \text { Total Dissolved Solids } \\ \end{array}$




\section{REFERENCES}

Ajayi, F. and Lyon, S. (2014), "Efficiency of Volatile Corrosion Inhibitors in Wet Gas Pipelines”, CORROSION 2014, San Antonio, USA, 9-13 March.

Amjad, Z., Landgraf, R. T. and Penn, J. L. (2014), “Calcium sulphate dihydrate (gypsum) scale inhibition by PAA, PAPEMP, and PAA/PAPEMP blend”, Int. J. Corros. Scale Inhib., Vol. 3, pp. 35-47

Anderko, A., Wang, P. A., Springer, R. D., Lencka, M. M. and Kosinski, J. J. (2010). Prediction Of Mineral Scaling In Oil And Gas Production Using A Comprehensive Thermodynamic Model. NACE International. San Antonio, Texas, 14 - 18 March, pp. 1-20.

Baraka-Lokmane, S., Hurtevent, C., Ohanessian, J.-L., Rousseau, G., Seiersten, M. E. and Deshmush, S. (2012), "Prediction of Mineral Scaling in a MEG Loop System of a Gas Production Offshore”, SPE International Conference on Oilfield Scale, Aberdeen, May 30-31

Bikkina, C., Radhakrishnan, N., Jaiswal, S., Harrington, R. and Charlesworth, M. (2012), "Development of MEG Regeneration Unit Compatible Corrosion Inhibitor for Wet Gas Systems”, SPE Asia Pacific Oil \& Gas Conference and Exhibition, Perth, Oct 22-24

Brustad, S., Løken, K. P. and Waalmann, J. G. (2005), "Hydrate Prevention using MEG instead of $\mathrm{MeOH}$ : Impact of Experience from Major Norwegian Developments on Technology Selection for Injection and Recovery of MEG, Offshore Technology Conference, Houston, Texas, May, 2-5.

Daraboina, N., Malmos, C. and von Solm, N. (2013), "Synergistic Kinetic Inhibition of Natural Gas Hydrate Formation”, Fuel, Vol. 108, pp. 749-757.

Davoudi, M., Safadoust, A. R., Mansoori, S.A. and Mottaghi, H.R. (2014), “The impurities effect on thermal degradation and corrosivity of amine solution in South Pars gas sweetening plants”, Journal of Natural Gas Science and Engineering, Vol. 19, pp. 116-124 
Esmaily, M., Shahabi-Navid, M., Svensson, J.E., Halvarsson, M., Nyborg, L., Cao, Y. and Johansson, L.G. (2015), "Influence of temperature on the atmospheric corrosion of the Mg-Al alloy AM50”, Corrosion Science, Vol. 90, pp. 420-433

Halvorsen, E. N., Halvorsen, A. M. K., Andersen, T. R., Reiersolmoen, K. and Biornstad, C. (2009). New Method for Scale Inhibitor Testing. SPE International Symposium on Oilfield Chemistry. The Woodlands, Texas, April, 20-22.

Harrington, R., M. Gough and S. Davoren (2011), "Development and Application of MEG Reclamation Process Compatible Corrosion Inhibitors for Upstream Oil and Gas Developments”, 18th International Corrosion Congress, Perth, Australia, November 20 - 24.

Hou, Z.B., Li, T.H., Lv, X.W. and Fu, B.G. (2015), "Influence of Imidazoline Inhibitor on $\mathrm{CO}_{2}$ Corrosion of N80 Steel in Annulus Zone of Pump Recovery Well”, Advanced Materials Research, Vol. 1061-1062, pp. 49-54

Jonassen, A. H. (2013), "Distribution of Hydrate Inhibitors in Processing of Gas Condensate”, Ph.D. Thesis, Norwegian University of Science and Technology, pp. 1-114

Kaasa, B. and Ostvold, T. (1996), “Alkalinity in Oil Field Waters. What Alkalinity is and How it is Measured", Oil Field Chemicals $7^{\text {th }}$ International Symposium, Geilo, Norway, March 17-20.

Kakadjian, S.R. and Thompson, J.E. (2014), “Oil Based Concentrated Slurries and Methods for making and using same”, United State Patent number US8728989 B2

Kan, A. and Tomson, M. (2012) "Scale Prediction for Oil and Gas Production", SPE Journal Vol. 17, pp. 1-17.

Kan, A. T., Fu, G. and Tomson, M. B. (2001), "Mineral-Scale Control in Subsea Completion”, Offshore Technology Conference. Houston, Texas, April 30.

Kelland, M. A. (2009), "Production chemicals for the oil and gas industry / Malcolm A. Kelland. Boca Raton, Boca Raton : CRC Press. 
Kobayashi, K., Liang, Y., Sakka, T. and Matsuoka, T. (2014), "Molecular Dynamics Study of Salt-Solution Interface: Solubility and Surface Charge of Salt in Water”, J. Chem. Phys., Vol. 140, pp. 144705-1 - 144705-8.

Latta, T. M., Seiersten, M. E. and Bufton, S. A. (2013), "Flow Assurance Impacts on Lean/Rich MEG Circuit Chemistry and MEG Regenerator/Reclaimer Design”, Offshore Technology Conference, Houston, Texas, May, 6-8.

Memon, M.K., Shuker, M.T. and Elraises, K. A. (2014), "Solubility of Foam Surfactants in High Divalent Ions at High Temperature”, J. of Applied Sciences, Vol. 14, pp. 3339-3343

Metrohm (2011), “Corrosion”, Autolab Application Note COR05, Pelican Creek Circle, $\begin{array}{llllll}\text { Florida, } & \text { Accessed } & \text { on } & 21 & \text { October } & 2014\end{array}$ through www.ecochemie.nl/download/Applicationnotes/Autolab_Application_Note_COR05. pdf

Nam, N.D.,Mathesh, M., Hinton, B., Tan, M. J. and Forsyth, M. (2014), "Rare Earth 4Hydroxycinnamate Compounds as Carbon Dioxide Corrosion Inhibitors for Steel in Sodium Chloride Solution”, J. Electrochem. Soc., Vol. 161, pp. C527-C534

Nazzer, C. A. and Keogh, J. (2006), “Advances in Glycol Reclamation Technology”, Offshore Technology Conference. Houston, U.S.A., 1-4 May, pp. 1-7.

Obanijesu, E.O, Barifcani, A., Pareek, V. and Tade, M.O. (2014a), "Experimental Study on Feasibility of $\mathrm{H}_{2}$ and $\mathrm{N}_{2}$ as Hydrate Inhibitors in Natural Gas Pipelines”, Journal of Chemical and Engineering Data, Vol. 59, pp 3756-3766

Obanijesu, E.O., Gubner, R., Barifcani, A., Pareek, V. and Tade, M.O. (2014b), "The Influence of Corrosion Inhibitors on Hydrate Formation Temperature along the Subsea Natural Gas Pipelines”, Journal of Petroleum Science and Engineering, Vol. 120, pp. 239252 
Psarrou, M. N., Josang, L. O., Sandengen, K. and Ostvold, T. (2011). "Carbon Dioxide Solubility and Monoethylene Glycol (MEG) Degradation at MEG Reclaiming/Regeneration Conditions." J. Chem. Eng. Data, Vol. 56, pp. 4720-4724.

Pitzer, K. S, Brewer, L. Lewis, G.N., Randall M. (1961), “Thermodynamics”, 2nd ed., McGraw-Hill, USA

Radke, C.J. (2014), “Gibbs Adsorption Equation for Planar Fluid-Fluid Interfaces: Invariant Formalism", Advances in Colloid and Interface Science, Article in Press (doi:10.1016/j.cis.2014.01.001)

Rossiter Jr, W. J., Brown, P. W. and Godette, M. (1983). "The Determination of Acidic degradation products in aqueous ethylene glycol and propylene glycol solutions using ion chromatography." Solar Energy Materials, Vol. 9, Iss. 3, pp. 267-279.

Sandengen, K. (2006). "Prediction of mineral scale formation in wet gas condensate pipelines and in meg (mono ethylene glycol) regeneration plants”, Ph.D. Thesis, Norwegian University of Science and Technology, Trondheim, pp. 1-209

Sandengen, K., Kaasa, B. and Østvold, T. (2007). "pH Measurements in Monoethylene Glycol (MEG) + Water Solutions." Industrial \& Engineering Chemistry Research, Vol. 46, pp. 4734-4739.

Seo, Y., Shin, K., Kim, H., Wood, C.D., Tian, W. and Kozielski, K.A. (2014), "Preventing Gas Hydrate Agglomeration with Polymer Hydrogels”, Energy Fuels, Vol. 28, pp. $4409-4420$

Sharifi, H., Walker, V.K., Ripmeester, J. and Englezos, P. (2014), "Insights into the Behavior of Biological Clathrate Hydrate Inhibitors in Aqueous Saline Solutions”, Cryst. Growth Des., Vol. 14, pp 2923-2930

Smith, J.M., Van Ness, H.C. and Abbott, M.M. (2004), "Introduction to Chemical Engineering Thermodynamics”, $7^{\text {th }}$ Edition, McGraw-Hills, New York. 
So, S. and Lodge, T.P. (2015), “Interfacial Tension-Hindered Phase Transfer of Polystyreneb-poly(ethylene oxide) Polymersomes from a Hydrophobic Ionic Liquid to Water”, Langmuir, Vol. 31, Iss. 1, pp 594-601

Sørli, J.G.H. (2010), “MEG Regeneration for Floating Production Units”, Aker Process Systems A. FPSO Seminar, Holmen Fjordhotell, Nesbru, Norway.

Van Son, K. and Wallace, C. (2000), "Reclamation/Regeneration of Glycols used for Hydrate Inhibition”, Deep Offshore Technology. New Orleans, USA, pp. 1-14.

Zhu, Z. and Lei, Y. (2015), "Effect of Chain Length of the Alkyl in Quaternary Ammonium Substituents on the Adhesion-to-Fiber, Aerobic Biodegradation, and Desizability of Quaternized Cornstarch”, Journal of Adhesion Science and Technology, Vol. 29, pp. 116-132 